\title{
Renal mucinous tubular and spindle carcinoma lacks the gains of chromosomes 7 and 17 and losses of chromosome $Y$ that are prevalent in papillary renal cell carcinoma
}

\author{
Paolo Cossu-Rocca ${ }^{1,2}$, John N Eble ${ }^{1}$, Brett Delahunt ${ }^{3}$, Shaobo Zhang ${ }^{1}$, Guido Martignoni ${ }^{2,4}$, \\ Matteo Brunelli ${ }^{2}$ and Liang Cheng ${ }^{1}$ \\ ${ }^{1}$ Departments of Pathology and Laboratory Medicine, Indiana University Medical Center, University \\ Hospital,Indianapolis, IN, USA; ${ }^{2}$ Dipartimento di Patologia, Universitá di Sassari, Sassari, Italy; ${ }^{3}$ Department \\ of Pathology and Molecular Medicine, Wellington School of Medicine, University of Otago, Wellington, \\ New Zealand and ${ }^{4}$ Dipartimento di Patologia, Universitá di Verona, Verona, Italy
}

\begin{abstract}
Mucinous tubular and spindle cell carcinoma of the kidney is an uncommon, distinctive neoplasm characterized by the proliferation of cuboidal and spindle cells arranged in tubular or sheet-like arrays, typically with a mucinous or myxoid background. The most important differential diagnostic consideration of mucinous tubular and spindle cell carcinoma is papillary renal cell carcinoma, type 1, with sarcomatoid transformation. The aim of our study is to investigate the pattern of possible gains or losses of chromosomes 7,17 and $Y$ in 10 mucinous tubular and spindle cell carcinomas with interphase fluorescence in situ hybridization (FISH). Four-micron sections were obtained from paraffin blocks representative of the tumors and including adjacent non-neoplastic renal parenchyma from 10 patients. The patients' ages ranged from 20 to 80 years (mean: 62 years); eight were female, while two were male. FISH analysis was performed with centromeric probes for chromosomes 7,17 and Y. One hundred fifty to 200 nuclei from each case were scored for hybridization signals and non-neoplastic parenchyma served as control tissue. We found that renal mucinous tubular and spindle carcinoma lacks the gains of chromosomes 7 and 17 and losses of chromosome $Y$ that are typical of papillary renal cell carcinoma. FISH analysis with centromeric probes for these chromosomes is potentially helpful in differentiating mucinous tubular and spindle cell carcinomas from papillary renal cell carcinomas.

Modern Pathology (2006) 19, 488-493. doi:10.1038/modpathol.3800565
\end{abstract}

Keywords: kidney; mucinous tubular and spindle cell carcinoma; cytogenetics; fluorescence in situ hybridization (FISH)

Renal mucinous tubular and spindle cell carcinomas are uncommon, distinctive neoplasms histologically characterized by the proliferation of small cuboidal and spindle cells, arranged in elongated tubules or sheets, typically associated with a mucinous background. ${ }^{1,2}$ Until its recognition as a distinct neoplastic entity by the World Health Organization (WHO) consensus conference, mucinous tubular and spindle cell carcinoma had been previously sporadically reported with a variety

Correspondence: Dr L Cheng, MD, Department of Pathology and Laboratory Medicine, Indiana University Medical Center, University Hospital 3465, 550 North University Blvd., Indianapolis, IN 46202, USA.

E-mail: lcheng@iupui.edu

Received 10 October 2005; revised 30 December 2005; accepted 3 January 2006 of names, usually pointing out the morphologic relationships with the distal nephron and the loop of Henle or highlighting the spindle cell component. $^{3-11}$

Since mucinous tubular and spindle cell carcinomas have generally been described as low-grade and low-stage malignancies, usually cured by surgery, ${ }^{1,4,8,12-14}$ differentiation from other primary malignancies of the kidney is important. The differential diagnosis has to take into consideration primarily papillary renal cell carcinoma, type 1 , that may share with mucinous tubular and spindle cell carcinomas several pathologic features, such as tubular, trabecular or papillary architecture, lowgrade or moderate nuclear atypia, and the presence of foamy macrophages and inflammatory cells. ${ }^{1,2,7,13,15-18}$ Furthermore, the occurrence of sarcomatoid change in papillary renal cell carcinomas 
enhances the potential for morphologic similarities between these carcinomas. ${ }^{16,19,20}$ Immunohistochemical analyses of mucinous tubular and spindle cell carcinomas have not identified a consistent expression profile useful in discriminating them from papillary carcinomas, ${ }^{2,4,7,9,13,21}$ and recent studies have found significant immunophenotypic similarities between these tumors. Both tumors frequently express cytokeratin 7, epithelial membrane antigen, high molecular weight cytokeratin and $\alpha$-methylacyl-CoA racemase. ${ }^{22}$

While genetic abnormalities in papillary renal cell carcinomas have been extensively studied, ${ }^{23-29}$ so far, genetic studies on mucinous tubular and spindle cell carcinomas are few and mainly based on comparative genomic hybridization..$^{9,13,30,31}$

Fluorescence in situ hybridization (FISH) has proved useful in distinguishing papillary renal cell carcinoma from metanephric adenoma, with which it may also be confused. ${ }^{32}$ Thus, we undertook to perform FISH analyses with centromeric probes for chromosome 7, 17 and Y on paraffin-embedded specimens from a series of mucinous tubular and spindle cell carcinomas to establish possible gains or losses for these chromosomes, and to assess the potential role for FISH in the differential diagnosis of mucinous tubular and spindle cell carcinoma from papillary renal cell carcinoma.

\section{Materials and methods}

\section{Specimens}

A total of 10 mucinous tubular and spindle cell carcinomas of the kidney were retrieved from the files of the Departments of Pathology of Indiana University Medical School, Indianapolis, USA, and Wellington University Medical School, Wellington, New Zealand.

\section{Tissue Preparations and Fluorescence In Situ Hybridization}

Four-micron section, were cut from paraffin blocks representative of the carcinoma proliferation and of the surrounding non-neoplastic renal parenchyma. The slides were deparaffinized with two washes of xylene, $15 \mathrm{~min}$ each, and subsequently washed twice with absolute ethanol, 10 min each and then air dried in the hood. Next, the slides were treated with $0.1 \mathrm{mM}$ citric acid (pH 6.0) (Zymed, CA, USA) at $95^{\circ} \mathrm{C}$ for $10 \mathrm{~min}$, rinsed in distilled water for $3 \mathrm{~min}$ followed by a wash of $2 \times$ SSC (standard saline citrate) for $5 \mathrm{~min}$. Digestion of the tissue was performed by applying $0.4 \mathrm{ml}$ of pepsin $(5 \mathrm{mg} / \mathrm{ml}$ in $0.9 \% \mathrm{NaCl}, \mathrm{pH} 1.5$ ) (Sigma, St Louis, MO, USA) at $37^{\circ} \mathrm{C}$ for $40 \mathrm{~min}$. The slides were rinsed with distilled water for $3 \mathrm{~min}$, then washed with $2 \times$ SSC for 5 min and air dried.
FISH was performed with centromeric $\alpha$-satellite DNA probes for chromosome 7 (Centromeric Enumeration Probe, CEP 7, Spectrum Green), chromosome 17 (CEP 17, Spectrum Orange) and chromosome Y (CEP 1, Spectrum Green). All the probes were from Vysis (Vysis, Downers Grove, IL, USA) and were diluted with tDenHyb1 (Insitus, Albuquerque, NM, USA) in a ratio of 1:75. Of diluted probe, $(5 \mu \mathrm{l})$ were applied to each slide in the reduced light condition. The slides were then covered with a $22 \times 22 \mathrm{~mm}^{2}$ coverslip and sealed with rubber cement. Denaturation was achieved by incubating the slides at $80^{\circ} \mathrm{C}$ for $10 \mathrm{~min}$ in a humidified box then hybridized at $37^{\circ} \mathrm{C}$ over night. The cover slip were removed and the slides were washed twice with $45^{\circ} \mathrm{C} 0.1 \times \mathrm{SSC} / 1.5 \mathrm{M}$ urea (20 min for each wash), followed by a wash with $2 \times$ SSC for $20 \mathrm{~min}$ and a wash with $2 \times \mathrm{SSC} /$ $0.1 \% \mathrm{NP} 40$ for $10 \mathrm{~min}$ at $45^{\circ} \mathrm{C}$. The slides were further washed with room temperature $2 \times$ SSC for $5 \mathrm{~min}$. The slides were air dried and counterstained with $10 \mu \mathrm{l}$ DAPI (Insitus, Albuquerque, NM, USA), covered with coverslips and sealed with nail polish.

The slides were examined using a Zeiss Axioplan 2 microscope (ZEISS, Göttingen, Germany) with the following filters: SP-100 DAPI, FITC MF-101 for Spectrum Green (CEP 7 and Y) and Gold 31003 for Spectrum Orange (CEP17) from Chroma (Chroma, Brattleboro, VT, USA). The images were acquired with a CCD camera and analyzed with MetaSystem Isis Software (MetaSystem, Belmont, MA, USA). Five to six sequential focus stacks with $0.4 \mu \mathrm{m}$ intervals were acquired and then integrated into a single image in order to reduce thickness-related artifacts.

\section{In Situ Hybridization Analysis}

The method of analysis was as previously described in detail. ${ }^{33}$ In brief, for each slide, from 150 to 250 nuclei were scored for signals from centromeric probes under the fluorescence microscope with $\times 1000$ magnification in both neoplastic and nonneoplastic areas. Signals from solitary nuclei were counted preferentially, but signals from adjacent, nonoverlapping nuclei were occasionally included in the counts. Two signals of the same size in close proximity, not connected by a link, were counted as two signals. A diffuse signal was regarded as a signal if it was contiguous and within an acceptable boundary. Two small signals connected by a visible link were counted as one signal. Overlapping nuclei and nuclei with uncertain signal were not included in the counts. Definition of chromosomal gain was based on the Gaussian model and based upon the non-neoplastic controls. The cutoff values for recognizing gains or loss of a chromosome were set at the mean values in the control tissue plus three standard deviations (s.d.). Any tumor with percen- 
tages of signals beyond the cutoff values was considered to have gain or loss of the chromosome.

\section{Results}

Clinico-pathologic data are summarized in Table 1. The patients' ages ranged from 20 to 80 years (mean: 62 years). Eight patients were female while two were male. The tumors varied from 35 to $160 \mathrm{~mm}$ in largest diameter. Pathologic stages were pT1a (two tumors), pT1b (five tumors) and pT2 (three tumors).

The control distribution of signals was assessed on non-neoplastic renal parenchyma adjacent to the tumors. For chromosome 7, the mean percentages of nuclei with one, two and three or more signals were 33,66 and $0.7 \%$, respectively, with respective s.d. of $2.9,3$ and $0.5 \%$. Therefore, the cutoff values to determine loss or gain of chromosome 7 were $42 \%$ for nuclei with single signals and $2.2 \%$ for nuclei with three or more signals (mean plus 3 s.d.). For chromosome 17, the mean percentages of nuclei in control tissue with one, two and three or more signals were $35.4,63.8$ and $0.8 \%$, respectively, with respective s.d. of $1.9,1.8$ and $0.5 \%$. Cutoff values for loss and gain of chromosome 17 were, respectively, $41 \%$ for nuclei with single signals and $2.3 \%$ for nuclei with three or more signals. Analyses of chromosome $\mathrm{Y}$ probes in control tissue from the

Table 1 Clinico-pathologic characteristics

\begin{tabular}{lcclcc}
\hline Case no. & Sex & Age & Stage & Size (mm) & Follow-up \\
\hline 1 & M & 80 & pT2 & 70 & NA \\
2 & M & 53 & pT2 & 135 & NA \\
3 & F & 70 & pT1b & 45 & NA \\
4 & F & 71 & pT2 & 130 & NA \\
5 & F & 67 & pT1b & 68 & NA \\
6 & F & 54 & pT1b & 60 & NA \\
7 & F & 62 & pT1a & 35 & NA \\
8 & F & 52 & pT1b & 58 & Alive (>60 months $)$ \\
9 & F & 73 & pT1a & 40 & Alive (>60 months) \\
10 & F & 36 & pT1b & 55 & Alive (>60 months) \\
& & & & &
\end{tabular}

NA: not available. two male patients showed percentages of nuclei with one signal in 80 and $78 \%$, respectively.

For chromosome 7 , in mucinous tubular and spindle cell carcinomas (Table 2), the prevalence of nuclei with two signals was essentially identical to the control in nine out of 10 tumors with results ranging from 60 to $70 \%$. Only one tumor (case 3) showed a lower percentage of $31 \%$. In nine of 10 tumors, nuclei with one signal accounted for percentages ranging from 28 to $36 \%$, while case 3 showed a higher percentage of $69 \%$. Nuclei with three or more signals were observed in percentages ranging from 0.5 to $2 \%$.

For chromosome 17, nuclei with two signals predominated in all tumors, with percentages ranging from 63 to $65 \%$. Nuclei with one signal were observed in percentages ranging from 28 to $36 \%$, whereas nuclei with three or more signals accounted for percentages from 1.4 to $2.3 \%$ in all tumors.

Chromosome $\mathrm{Y}$ was present in both the two tumors from male patients, with percentages of 81 and $80 \%$ (Figure 1).

\section{Discussion}

In this study, we found that mucinous tubular and spindle cell carcinomas lack the consistent gains of chromosomes 7 and 17 and losses of chromosome Y, that are prevalent in papillary renal cell carcinomas. Genetic studies of mucinous tubular and spindle cell carcinomas are few. Rakozy et $a l^{13}$ analyzed six tumors from five patients with comparative genomic hybridization techniques and demonstrated multiple genetic abnormalities which included consistent losses of chromosomes 1, 4, 6, 8, 9, 13, 14, 15 and 22 in all cases, and these results were corroborated by $\mathrm{LOH}$ analyses in all informative cases. Srigley et $a l^{9}$ reported in abstract form genetic analyses on 10 cases of mucinous tubular and spindle cell carcinomas that were investigated with both CGH and FISH methodologies. In eight out of 10 cases, frequent losses for chromosomes 1, 4q, 6, 8p, 9p, 11q, 13, 14 and 15, and gains for chromosomes 12q, 16q 17 and 20q were identified by CGH analyses. FISH con-

Table 2 Percentages of nuclei with hybridization signals in mucinous tubular and spindle cell carcinomas

\begin{tabular}{|c|c|c|c|c|c|c|c|c|}
\hline \multirow[t]{2}{*}{ Case } & \multicolumn{3}{|c|}{ Chromosome 7} & \multicolumn{3}{|c|}{ Chromosome 17} & \multicolumn{2}{|c|}{ Chromosome $Y$} \\
\hline & 1 signal (\%) & 2 signals (\%) & $\geq 3$ signals $(\%)$ & 1 signal (\%) & 2 signals (\%) & $\geq 3$ signals $(\%)$ & 1 signal & 0 signal (\%) \\
\hline 1 & 33 & 66 & 1 & 32 & 66 & 2 & $81 \%$ & 19 \\
\hline 2 & 33 & 66 & 1 & 36 & 62.6 & 1.4 & $80 \%$ & 20 \\
\hline 3 & 69 & 30.5 & 0.5 & 31 & 67 & 2 & Female & \\
\hline 4 & 28 & 71 & 1 & 27.5 & 71 & 1.5 & Female & \\
\hline 5 & 31 & 68 & 1 & 33 & 65 & 2 & Female & \\
\hline 6 & 36 & 62 & 2 & 33 & 65 & 2 & Female & \\
\hline 7 & 35 & 64 & 1 & 34.7 & 63 & 2.3 & Female & \\
\hline 8 & 34 & 64 & 2 & 31 & 67 & 2 & Female & \\
\hline 9 & 36 & 62 & 2 & 33 & 65 & 2 & Female & \\
\hline 10 & 31 & 67 & 2 & 32 & 66 & 2 & Female & \\
\hline
\end{tabular}


firmed chromosomal deletions in a subset of tumors, but no deletions for von Hippel Lindau (VHL) gene on chromosome $3 \mathrm{p}$ were appreciable. ${ }^{9}$ Weber et al performed genetic analysis with CGH on eleven mucinous tubular and spindle cell carcinomas, describing multiple losses of chromosomes 1, 4, 6, $8 p, 9 p, 13$ and 14, while an apparent gain of chromosome 17 was observed in three cases. Subsequently, they evaluated all eleven cases by FISH with centromeric probes to verify gains and losses
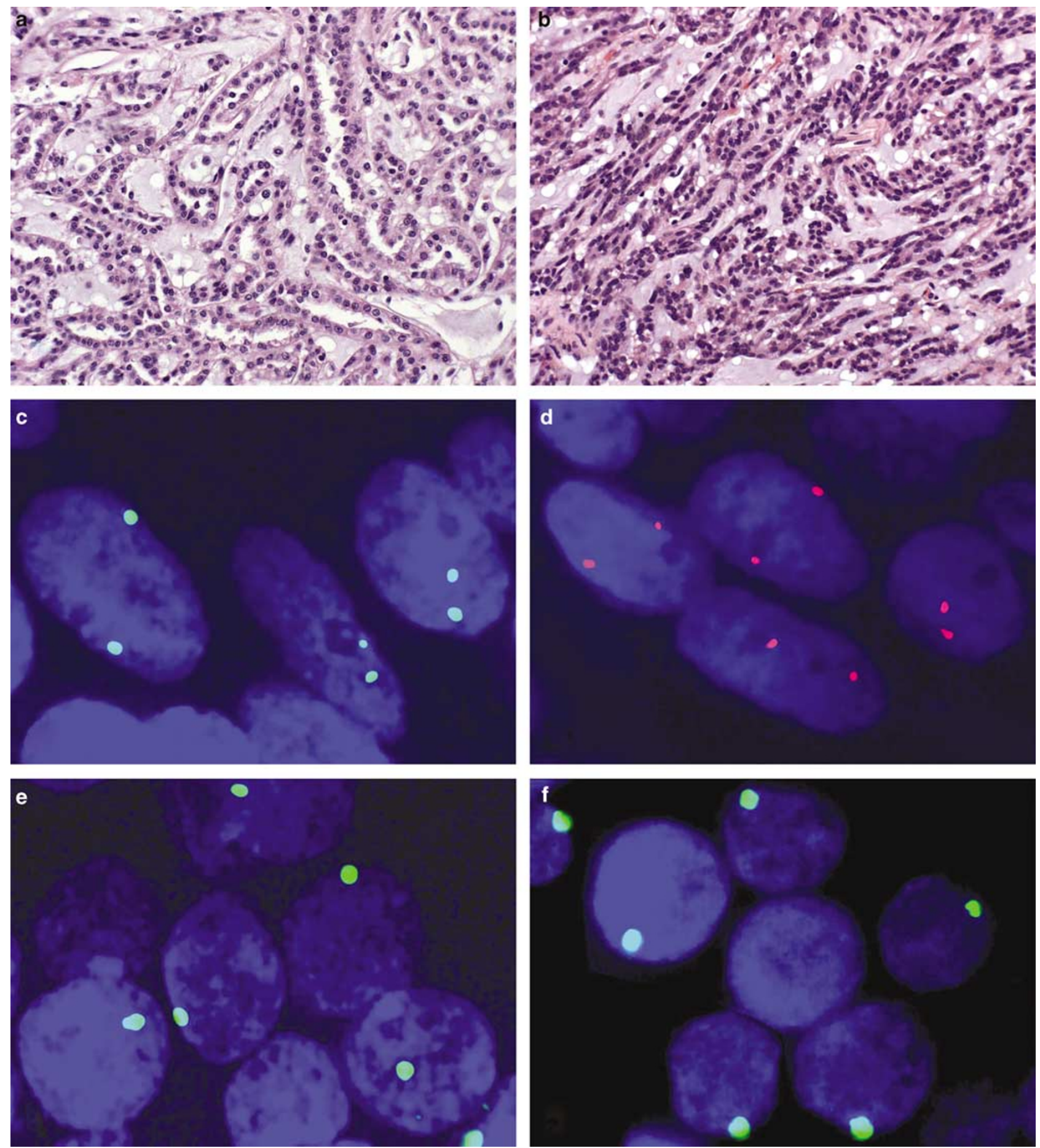

Figure 1 FISH analysis in renal mucinous tubular and spindle carcinoma. (a) Classic renal mucinous tubular and spindle cell carcinoma showing small, elongated tubular structures composed by small cuboidal cells, with basophilic mucinous stroma. (b) Tumor cells with spindle appearance, arranged in sheets or cords. (c) FISH with centromeric probe for chromosome 7 displaying nuclei with two hybridization signals. (d) FISH with centromeric probe for chromosome 17 showing nuclei with two hybridization signals. (e) FISH with centromeric probe for chromosome 7 in case 3, showing nuclei with a single hybridization signal, consistent with chromosomal loss and (f) FISH with centromeric probe for chromosome Y in a tumor from a male patient, showing nuclei with a single hybridization signal. 
for chromosomes $1,6,7$ and 17 , and to identify possible VHL gene alterations on chromosome $3 \mathrm{p}$. FISH analyses confirmed losses of chromosome 1 and 6, but could not confirm chromosomal gains for chromosome 17, as showed by CGH, nor for chromosome 7. Further, no evidence for VHL gene deletions was found.$^{30}$ Recently, an additional case of mucinous tubular and spindle cell carcinoma has been investigated by Ferlicot et al with CGH, demonstrating losses of chromosomes 1, 4, 6, 8, 13, 14,15 and $18 .^{31}$

All the studies reported above are in agreement that mucinous tubular and spindle cell carcinomas are prone to multiple losses of different chromosomes, detectable by either CGH or FISH analyses. While no chromosomal abnormalities have been identified in regard to chromosome 7 in any of the previous studies, CGH and FISH have shown contradictory results for chromosome 17 . Our findings are in accord with previous FISH-based analyses, since we found no gains of either chromosome 7 or 17 by FISH in any of the 10 mucinous tubular and spindle cell carcinomas. All but one of the tumors showed percentages of nuclei with three or more signals for centromeric probes of chromosomes 7 and 17 which were below the cutoff values; only one tumor had a percentage of nuclei with three or more signals for chromosome 17 matching the cutoff value of $2.3 \%$, while this qualified as a gain, in papillary adenomas, three or more signals were observed in $10-47 \%$ of nuclei and in papillary carcinomas in $28-61 \%$ of nuclei. ${ }^{25}$ We also report loss of chromosome 7 in one tumor. No loss of chromosome $\mathrm{Y}$ was found in the two cases from male patients (Figure 1).

While genetic features of mucinous tubular and spindle cell carcinomas have been studied in only a few reports, the genetic profile of papillary renal cell carcinomas has been assessed in several studies, which found that gains of chromosome 7 and 17 and loss of Y may be considered as a genetic hallmark for these variants. These chromosomal abnormalities occur early in the evolution of papillary renal cell neoplasia and are often associated with further gains of chromosomes 12,16 and $20 .^{17,23-28,34-36}$ The typical gains of chromosome 7 and 17 and loss of $\mathrm{Y}$ in papillary renal cell carcinomas have been observed in several FISH-based studies, and FISH analyses with centromeric probes for chromosomes 7, 17 and $\mathrm{Y}$ have been previously proposed to have a potential role in the differential diagnosis of papillary renal cell tumors with metanephric adenomas. $^{25,27,32,35,37}$ Furthermore, recent studies performed with multicolor FISH confirmed the typical chromosomal abnormalities described in papillary renal cell carcinomas and interphase FISH may be considered as a sensitive and specific technique for a rapid and accurate identification of distinctive genetic abnormalities, that are potentially useful in the distinction of the different histotypes of renal cell carcinomas. ${ }^{38,39}$
In conclusion, analysis of chromosomes 7, 17 and $\mathrm{Y}$ by FISH with centromeric probes showed that mucinous tubular and spindle cell carcinomas lack the gains of chromosomes 7 and 17 and losses of chromosome $\mathrm{Y}$, that are prevalent in papillary renal cell carcinomas, and may be helpful in the differential diagnosis with classic and sarcomatoid papillary renal cell carcinomas.

\section{References}

1 Srigley J. Mucinous tubular and spindle cell carcinoma. In: Eble JN, Sauter G, Epstein JI, Sesterhenn IA (eds). World Health Organization Classification of Tumours: Pathology and Genetics of Tumours of the Urinary System and Male Genital Organs. IARC Press: Lyon, 2004, p 40.

2 Eble JN. Mucinous tubular and spindle cell carcinoma and post-neuroblastoma carcinoma: newly recognised entities in the renal cell carcinoma family. Pathology 2003;35:499-504.

3 He Q, Ohaki Y, Mori O, et al. A case report of renal cell tumor in a 45-year-old female mimicking lower portion nephrogenesis. Pathol Int 1998;48:416-420.

4 Hes O, Hora M, Perez-Montiel DM, et al. Spindle and cuboidal renal cell carcinoma, a tumour having frequent association with nephrolithiasis: report of 11 cases including a case with hybrid conventional renal cell carcinoma/spindle and cuboidal renal cell carcinoma components. Histopathology 2002;41:549-555.

5 Lloreta J, Corominas JM, Munne A, et al. Low-grade spindle cell carcinoma of the kidney. Ultrastruct Pathol 1998;22:83-90.

6 Otani M, Shimizu T, Serizawa H, et al. Low-grade renal cell carcinoma arising from the lower nephron: a case report with immunohistochemical, histochemical and ultrastructural studies. Pathol Int 2001;51:954-960.

7 Parwani AV, Husain AN, Epstein JI, et al. Low-grade myxoid renal epithelial neoplasms with distal nephron differentiation. Hum Pathol 2001;32:506-512.

8 Srigley J, Eble JN, Grignon DJ, et al. Unusual renal cell carcinoma (RCC) with prominent spindle cell change possibly related to the loop of Henle. Mod Pathol 1999;12:107A.

9 Srigley J, Kapusta L, Reuter V, et al. Phenotypic, molecular, and ultrastructural studies of a novel lowgrade renal epithelial neoplasm possibly related to the loop of Henle. Mod Pathol 2002;15:182A.

10 MacLennan GT, Bostwick DG. Tubulocystic carcinoma, mucinous tubular and spindle cell carcinoma, and other recently described rare renal tumors. Clin Lab Med 2005;25:393-416.

11 MacLennan GT, Farrow GM, Bostwick DG. Low-grade collecting duct carcinoma of the kidney: report of 13 cases of low-grade mucinous tubulocystic renal carcinoma of possible collecting duct origin. Urology 1997;50:679-684.

12 Aubert S, Duchene F, Augusto D, et al. Low-grade tubular myxoid renal tumors: a clinicopathological study of 3 cases. Int J Surg Pathol 2004;12:179-183.

13 Rakozy C, Schmahl GE, Bogner S, et al. Low-grade tubular-mucinous renal neoplasms: morphologic, immunohistochemical, and genetic features. Mod Pathol 2002;15:1162-1171. 
14 Kuroda N, Toi M, Hiroi M, et al. Review of mucinous tubular and spindle-cell carcinoma of the kidney with a focus on clinical and pathobiological aspects. Histol Histopathol 2005;20:221-224.

15 Amin MB, Corless CL, Renshaw AA, et al. Papillary (chromophil) renal cell carcinoma: histomorphologic characteristics and evaluation of conventional pathologic prognostic parameters in 62 cases. Am J Surg Pathol 1997;21:621-635.

16 Delahunt B, Eble JN. Papillary renal cell carcinoma: a clinicopathologic and immunohistochemical study of 105 tumors. Mod Pathol 1997;10:537-544.

17 Kuroda N, Toi M, Hiroi M, et al. Review of papillary renal cell carcinoma with focus on clinical and pathobiological aspects. Histol Histopathol 2003;18: 487-494.

18 Val-Bernal JF, Gomez-Roman JJ, Vallina T, et al. Papillary (chromophil) renal cell carcinoma with mucinous secretion. Pathol Res Pract 1999;195:11-17.

19 Cohen RJ, McNeal JE, Susman M, et al. Sarcomatoid renal cell carcinoma of papillary origin. A case report and cytogenic evaluation. Arch Pathol Lab Med 2000;124:1830-1832.

20 de Peralta-Venturina M, Moch H, Amin M, et al. Sarcomatoid differentiation in renal cell carcinoma: a study of 101 cases. Am J Surg Pathol 2001;25:275-284.

21 Skinnider BF, Folpe AL, Hennigar RA, et al. Distribution of cytokeratins and vimentin in adult renal neoplasms and normal renal tissue: potential utility of a cytokeratin antibody panel in the differential diagnosis of renal tumors. Am J Surg Pathol 2005;29: 747-754.

22 Paner GP, Srigley JR, Young AN, et al. Immunohistochemistry in the differential diagnosis of mucinous tubular and spindle cell carcinoma and papillary renal cell carcinoma of the kidney: innovations and pitfalls. Mod Pathol 2005;18:157A.

23 Kovacs G. Papillary renal cell carcinoma. A morphologic and cytogenetic study of 11 cases. Am J Pathol 1989;134:27-34.

24 Kovacs G, Fuzesi L, Emanual A, et al. Cytogenetics of papillary renal cell tumors. Genes Chromosomes Cancer 1991;3:249-255.

25 Brunelli M, Eble JN, Zhang S, et al. Gains of chromosomes 7, 17, 12, 16, and 20 and loss of Y occur early in the evolution of papillary renal cell neoplasia: a fluorescent in situ hybridization study. Mod Pathol 2003;16:1053-1059.

26 Jiang F, Richter J, Schraml P, et al. Chromosomal imbalances in papillary renal cell carcinoma: genetic differences between histological subtypes. Am J Pathol 1998;153:1467-1473.

27 Corless CL, Aburatani H, Fletcher JA, et al. Papillary renal cell carcinoma: quantitation of chromosomes 7 and 17 by FISH, analysis of chromosome $3 p$ for $\mathrm{LOH}$ and DNA ploidy. Diagn Mol Pathol 1996;5:53-64.

28 Henke RP, Erbersdobler A. Numerical chromosomal aberrations in papillary renal cortical tumors: relationship with histopathologic features. Virchows Arch 2002;440:604-609.

29 Hughson MD, Dickman K, Bigler SA, et al. Clear-cell and papillary carcinoma of the kidney: an analysis of chromosome 3,7 , and 17 abnormalities by microsatellite amplification, cytogenetics, and fluorescence in situ hybridization. Cancer Genet Cytogenet 1998;106: 93-104.

30 Weber A, Srigley J, Moch H. Mucinous spindle cell carcinoma of the kidney. A molecular analysis. Pathologe 2003;24:453-459.

31 Ferlicot S, Lupo A, Lazure T, et al. A novel entity: lowgrade mucinous tubular renal carcinoma. Histopathology 2005;47:218-219.

32 Brunelli M, Eble JN, Zhang S, et al. Metanephric adenoma lacks the gains of chromosomes 7 and 17 and loss of $\mathrm{Y}$ that are typical of papillary renal cell carcinoma and papillary adenoma. Mod Pathol 2003;16:1060-1063.

33 Brunelli M, Eble JN, Zhang S, et al. Eosinophilic and classic chromophobe renal cell carcinomas have similar frequent losses of multiple chromosomes from among chromosomes $1,2,6,10$, and 17 , and this pattern of genetic abnormality is not present in renal oncocytoma. Mod Pathol 2005;18:161-169.

34 Sanders ME, Mick R, Tomaszewski JE, et al. Unique patterns of allelic imbalance distinguish type 1 from type 2 sporadic papillary renal cell carcinoma. Am J Pathol 2002;161:997-1005.

35 Kattar MM, Grignon DJ, Wallis T, et al. Clinicopathologic and interphase cytogenetic analysis of papillary (chromophilic) renal cell carcinoma. Mod Pathol 1997;10:1143-1150.

36 Gunawan B, von Heydebreck A, Fritsch T, et al. Cytogenetic and morphologic typing of 58 papillary renal cell carcinomas: evidence for a cytogenetic evolution of type 2 from type 1 tumors. Cancer Res 2003;63:6200-6205.

37 Lager DJ, Huston BJ, Timmerman TG, et al. Papillary renal tumors. Morphologic, cytochemical, and genotypic features. Cancer 1995;76:669-673.

38 Receveur AO, Couturier J, Molinie V, et al. Characterization of quantitative chromosomal abnormalities in renal cell carcinomas by interphase four-color fluorescence in situ hybridization. Cancer Genet Cytogenet 2005;158:110-118.

39 Sanjmyatav J, Rubtsov N, Starke H, et al. Identification of tumor entities of renal cell carcinoma using interphase fluorescence in situ hybridization. J Urol 2005;174:731-735. 